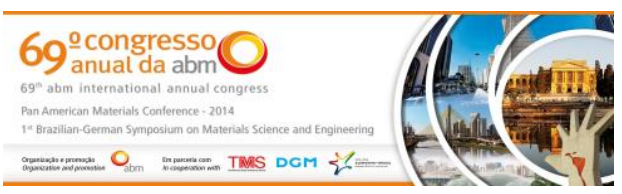

Tema: Iniciação científico-tecnológica

\title{
CARACTERIZAÇÃO DO FENÔMENO DE CREPITAÇÃO DE MINÉRIOS GRANULADOS DE FERRO AMOSTRADOS NOS SILOS DE ALIMENTAÇÃO*
}

\author{
Rafael Eduardo Gomes Ribeiro' \\ Breno Moreira ${ }^{2}$ \\ Leonardo Lúcio de Araújo Gouveia ${ }^{3}$ \\ Leonardo Neves ${ }^{4}$ \\ Ricardo Luiz Perez Teixeira ${ }^{5}$
}

\section{Resumo}

O fenômeno de degradação granulométrica de minérios devido à crepitação se apresenta como uma fonte geradora de finos que em excesso prejudica a permeabilidade da carga e diminui o rendimento da produção. Neste trabalho, realizou-se um estudo da crepitação de minérios de ferro da Sidermin (Siderúrgica Mineira) para dois períodos diferentes de 8 dias cada, num primeiro período o mecanismo de secagem do minério estava ativo e no outro seguinte não estava. Os resultados para crepitação foram satisfatórios pelo processo de pré-secagem do minério de ferro com gás de topo, pois resultou num aumento de produção por amenizar o fenômeno de crepitação.

Palavras-chave: Gases de exaustão; Alto-forno; Crepitação do minério de ferro; Pré-aquecimento da matéria-prima.

\section{DESCRIPTION OF THE PHENOMENON DECREPITATION GRANULES IRON ORE IN SILOS SAMPLED SUPPLY}

\section{Abstract}

The phenomenon of ore particle size degradation due to decrepitation results on the production of fine particles which in excess affect negatively the load permeability. As a consequence of that, the yeld is reduced. On this paper an iron ore decrepitation phenomenon study was conduced at Sidermin (Mineira Stell Mill) during 16 days equally divided into two steps, each one of 8 days. During the first period of time the dried mechanism was actived whether in the other one was not. The decrepitation results were satisfactory when utilizing the pre dryed iron ore with top reliever gas since it resulted in yeld gain due to the decrease of the decrepitation process.

Keywords: Exhaust gases; Blast furnace; Iron ore decrepitation; Raw material preheating.

1 Graduando, curso de Eng. Metalúrgica, Universidade do Estado de Minas Gerais (UEMG), João Monlevade, MG, Brasil.

2 Gerente de Produção, Sidermin Siderúrgica Mineira, Sete Lagoas, MG, Brasil.

3 Professor assistente, UEMG, João Monlevade, MG, Brasil.

4 Professor adjunto, UEMG e Pontifícia Universidade Católica de Minas Gerais, João Monlevade, MG, Brasil.

5 Professor de materiais metálicos, Universidade Federal de Itajubá, Campus Avançado de Itabira, Itabira, MG, Brasil.

\footnotetext{
* Contribuição técnica ao $69^{\circ}$ Congresso Anual da ABM - Internacional e ao 14ํㅡㄹ ENEMET - Encontro Nacional de Estudantes de Engenharia Metalúrgica, de Materiais e de Minas, 21 a 25 de julho de 2014, São Paulo, SP, Brasil.
} 


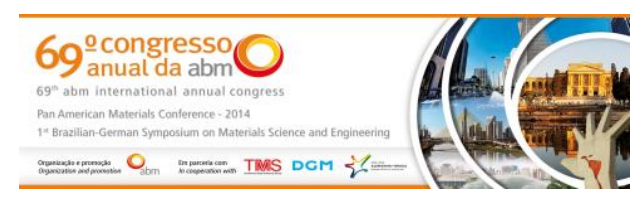

\section{INTRODUÇÃO}

O fenômeno de degradação granulométrica de minérios, que ocorre durante o aquecimento, é denominado crepitação, o mesmo se apresenta como uma fonte geradora de finos, que em excesso prejudica a permeabilidade da carga.

O primeiro a estudar este fenômeno foi Birnbaum [1], na década de 1960. Uma das primeiras hipóteses é que a crepitação está associada à vaporização brusca de água contida nos poros dos minérios. Segundo 0 autor, a degradação granulométrica só ocorreria em amostras úmidas, apesar do fato de existirem minérios que mesmo úmidos não apresentam o fenômeno.

Kunii et al argumentada em seus trabalhos é de que a água de cristalização foi o fator responsável pela crepitação de alguns dos minérios utilizados. A pressão de vapor, resultante da decomposição de fases minerais hidratadas, principalmente da goethita, gera tensões suficientemente grandes para romper o minério, a depender dos tipos de poros, Kunii [2].

De acordo com Faria [3], a crepitação de minérios de ferro é uma característica metalúrgica frequentemente considerada para fins de controle de qualidade de cargas de altos-fornos, visto que a degradação granulométrica do minério é indesejada no processo de redução.

A crepitação ocorre uma única vez em cada partícula de minério de ferro, de forma que, uma vez submetida a um choque térmico ou pré-tratamento térmico, caso experimente outros, não será verificada uma nova degradação granulométrica.

Vários estudos tem descrito a importância da secagem e tratamento térmico de granulados de minério de ferro para uso em reatores de redução. Vieira et al. [4] descreveu a tecnologia JB (iniciais do autor) de secagem e tratamento térmico de granulados, já empregadas em usinas brasileiras. A concepção básica consiste em empregar o silo de estocagem de matérias-primas como reator metalúrgico vertical em contracorrente, com a carga sólida no sentido descendente e gases quentes, gerados pela planta, no sentido ascendente. Segundo o autor esta tecnologia minimiza dois problemas, primeiramente, os gases quentes secam o minério, aumentando de forma acentuada a eficiência do peneiramento e a distribuição de carga no interior do reator, como depende da temperatura dos gases e do tempo de residência do minério no silo, poderá ocorrer uma diminuição da intensidade de crepitação no minério de ferro no interior do alto-forno.

O gás de alto-forno é um coproduto da produção do ferro-gusa, tem alto poder calorífico e não é utilizado em sua totalidade, sendo sua maior parte queimada e liberada na atmosfera. Estudos da Companhia Energética de Minas Gerais [5] mostraram que o volume total de gases gerados nos altos-fornos e fornos elétricos de redução instalados em Minas Gerais corresponde, em 2009, a 1.671 mil Toneladas Equivalentes de Petróleo (TEP). Esse valor representa 5,3\% da demanda total de energia do Estado de Minas Gerais, da ordem de grandeza do consumo total de eletricidade do setor Industrial.

A utilização do mecanismo de secagem do minério de ferro pelo gás de topo permitirá a otimização energética do processo siderúrgico pelo reaproveitamento do gás de alto-forno a carvão vegetal como energia no pré-aquecimento das matérias primas.

Desta forma o estudo visa a utilização do gás de topo do alto-forno como uma forma de reduzir o fenômeno de crepitação do minério de ferro.

\footnotetext{
* Contribuição técnica ao 69 Congresso Anual da ABM - Internacional e ao $14^{\circ}$ ENEMET - Encontro Nacional de Estudantes de Engenharia Metalúrgica, de Materiais e de Minas, 21 a 25 de julho de 2014, São Paulo, SP, Brasil.
} 


\section{METODOLOGIA}

O estudo foi realizado na Sidermin-Siderúrgica Mineira, que possui dois altos-fornos a carvão vegetal, localizada na cidade de Sete Lagoas-MG.

Para analisar a eficiência do secador de minério foi observada a permeabilidade da carga do alto-forno 2.

A permeabilidade é um índice que quantifica a facilidade de escoamento dos gases pelo corpo do alto-forno. A fórmula matemática utilizada para o seu cálculo foi expressa por Araújo [6].

$$
P c=\frac{V g}{(P s-P t)}
$$

$\mathrm{P}_{\mathrm{c}}=$ permeabilidade da carga $\left(\mathrm{Nm}^{3} / \mathrm{h} . \mathrm{atm}\right)$;

$V_{g}=$ volume de gás que atravessa o forno por unidade de tempo $\left(\mathrm{Nm}^{3} / \mathrm{h}\right)$;

$P_{s}=$ pressão do ar no alto-forno (atm);

$\mathrm{P}_{\mathrm{t}}=$ pressão do gás no topo do alto-forno (atm).

Essa siderúrgica utiliza dois tipos de minérios de ferro, que após coletadas amostras desses minérios, foram feitas análises nas propriedades físicas quando submetidas a temperatura de $700^{\circ} \mathrm{C}$.

Foram retiradas amostras direto do silo de alimentação, ou seja, o minério que estava para ser enfornado, e foram realizados testes de crepitação seguindo a ISO/CD 8731[7].

Os ensaios foram feitos de acordo a norma ISO 8731, salvo as peneiras que eram de malhas diferentes visando atender a faixa granulométrica ideal para pequenos altos-fornos. A norma ISO 8731, em sua versão publicada em 2004, segue os seguintes procedimentos: A faixa granulométrica recomendada está entre $20 \mathrm{~mm}$ e $25 \mathrm{~mm}$, faz-se uso de dez alíquotas de $500 \mathrm{~g}$, secas a $(105 \pm 5)^{\circ} \mathrm{C}$ e peneiradas em $20 \mathrm{~mm}$ para eliminação dos finos. As alíquotas são depositadas em fornos tipo mufla a $700^{\circ} \mathrm{C}$ onde permanecem por 30 minutos. Depois de resfriadas ao ar, as alíquotas são individualmente peneiradas nas malhas de $6,3(1 / 4) ; 3,35(1 / 8)$ e $0,6(1 / 32)$. 0 índice de crepitação é determinado por meio da média aritmética das porcentagens em massa de material abaixo de 6,3mm. A equação (2), (3) e (4) são utilizadas para o calculo da média aritmética.

$$
I_{6,3}=100 \times \frac{m 2}{m 1}
$$

A variável $m_{2}$ é a massa de material abaixo de $6,3 \mathrm{~mm}$. A variável $\mathrm{m}_{1}$ é a massa total da alíquota após o choque térmico.

$$
I_{3,35}=100 \times \frac{m 2}{m 1}
$$

$\mathrm{Na}$ equação (3), m3,35 é a massa de material abaixo de $3,4 \mathrm{~mm}$. A variável $\mathrm{m}_{1}$ é a massa total da alíquota após o choque térmico.

$$
I_{0,6}=100 \times \frac{m 2}{m 1}
$$

\footnotetext{
* Contribuição técnica ao $69^{\circ}$ Congresso Anual da ABM - Internacional e ao 14ํㅡㄹ ENEMET - Encontro Nacional de Estudantes de Engenharia Metalúrgica, de Materiais e de Minas, 21 a 25 de julho de 2014, São Paulo, SP, Brasil.
} 


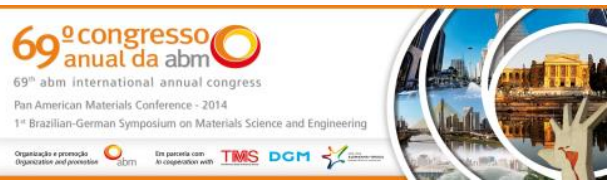

Já na equação (4) $\mathrm{m}_{0,6}$ é a massa de material abaixo de $0,6 \mathrm{~mm}$. A variável $\mathrm{m} 1$ é a massa total da alíquota após o choque térmico.

Baseado nos estudos de Vieira [8] e em dados coletados da empresa, foram feitos levantamentos da economia pelos benefícios gerados pelo mecanismo de secagem do minério.

\section{RESULTADOS E DISCUSSÃO}

Foram realizadas em julho de 2013 avaliações da produção do alto-forno 2 da Sidermin- Siderurgica Mineira em dois período diferentes, do dia 15 a 22 o alto-forno funcionou normalmente, já no período do 23 a 30 o mêcanismo de secagem de minério foi desativado, com esses dados foi possível fazer uma relação da produção quanto a utilização do gás de topo para secagem do minério de ferro.

Dados da produção foram catalogados e na figura 1, foi feita uma relação da influência da crepitação no ritmo de produção.

Durante esse período foram utilizadas as matérias primas apresentadas na tabela 1 abaixo.

Tabela 1 - Análise de Materia Prima em \% em peso (Dados Sidermin de 2013)

\begin{tabular}{|c|c|c|c|c|c|c|c|}
\hline \multicolumn{7}{|c|}{ ANÁLISE DA MATÉRIA PRIMA (\%) } \\
\hline Matéria Prima & Fe & SiO2 & Al2O3 & CaO MgO & Mn & P & $\%$ \\
\hline Minério A & 60,54 & 7,12 & 2,16 & - & 0,10 & 0,064 & 40,00 \\
\hline Minério B & 60,72 & 6,38 & 2,13 & - & 0,05 & 0,069 & 40,00 \\
\hline Briquete & 72,00 & 3,52 & 0,30 & 7,89 & 0,78 & 0,110 & 20,00 \\
\hline Calcário & - & 1,32 & - & 51,89 & - & - & - \\
\hline Sílica & - & 95,00 & - & - & - & - & - \\
\hline Sucata de Aço & 60,00 & 3,00 & 2,00 & 15,00 & - & 20,00 & - \\
\hline
\end{tabular}

A tabela acima apresenta a composição química da matéria prima utilizada no período de estudo, sendo o minério de ferro o insumo analisado.

Na figura 1, é mostrado o levantamento da produção diária do alto forno 2 em seu funcionamento normal, ou seja, com o secador de minérios ativo.

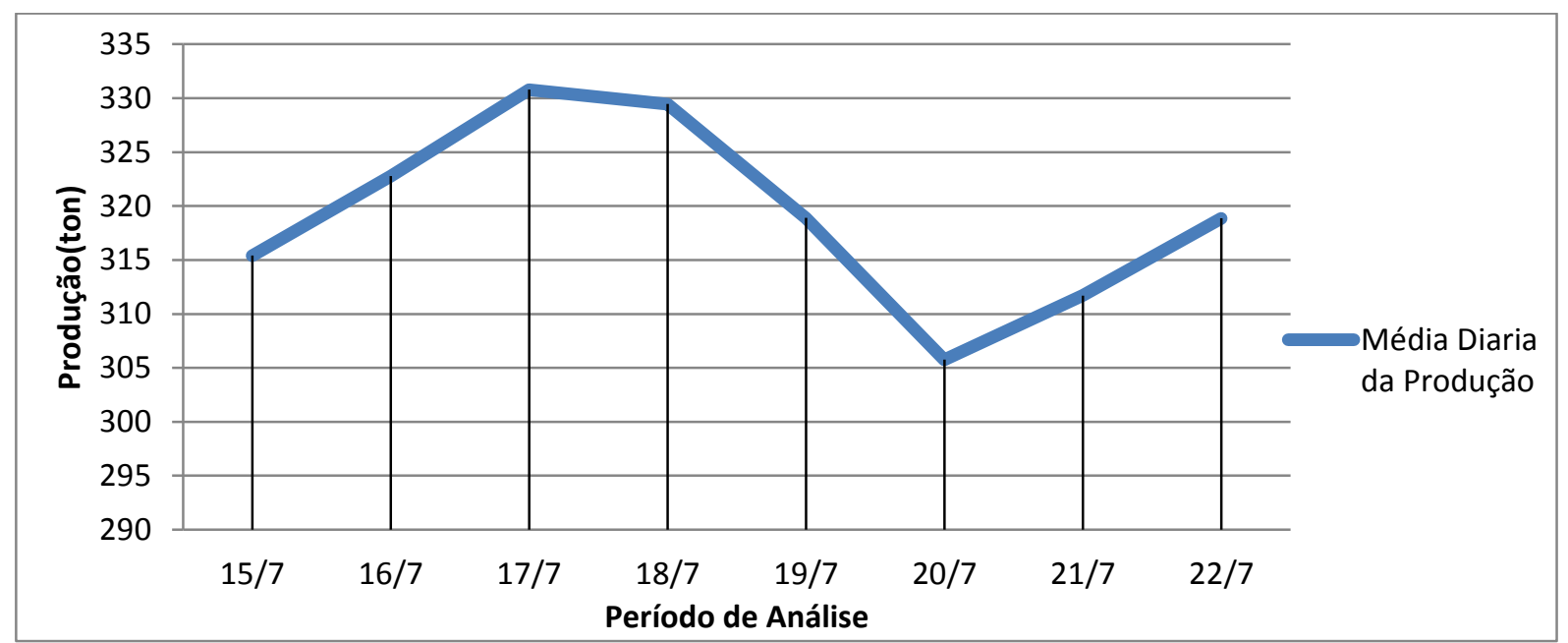

Figura 1 - Produção com Secador de Minérios Ativo. Fonte: Dados Sidermin de 2013

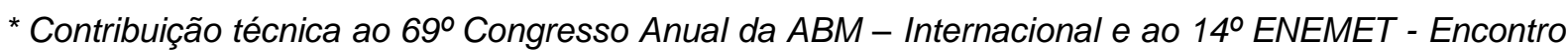
Nacional de Estudantes de Engenharia Metalúrgica, de Materiais e de Minas, 21 a 25 de julho de 2014, São Paulo, SP, Brasil. 


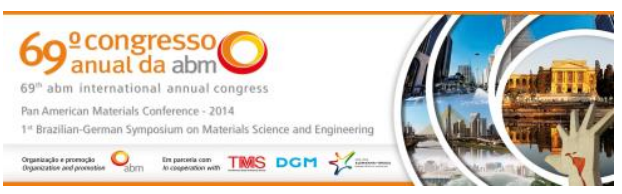

O Alto-Forno 2 tem como meta diária de produção um valor acima de 310 toneladas, no período exemplificado na figura 1 é possível observar que a meta foi alcançada, sendo que as variações de produção observadas no gráfico são decorrentes da qualidade do carvão vegetal.

Um fator importante e que tem grande influência no ritmo de produção é a permeabilidade da carga, ela é responsável pela passagem do gás redutor em contra corrente pelo alto-forno, ou seja, de baixo para cima, a carga desce e o gás sobe, quando há uma grande geração de finos a permeabilidade do alto-forno fica comprometida, diminuindo o ritmo da produção.

Na figura 2, é possível analisar a permeabilidade do período do dia 15 a 22.

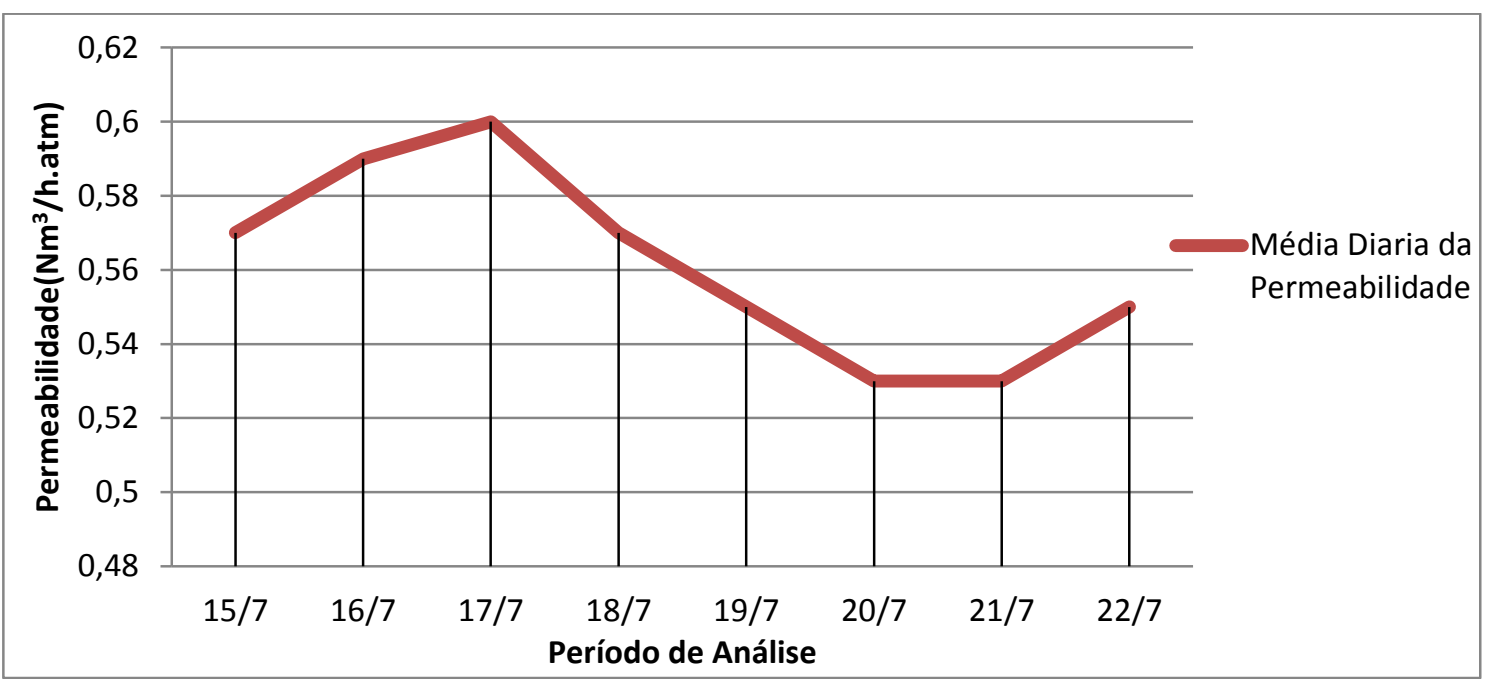

Figura 2 - Permeabilidade com Secador de Minérios Ativo. Fonte: Dados Sidermin, 2013.

É possível verificar que nos períodos de menor permeabilidade a produção diária foi menor.

Analisando a figura 1 e figura 2 fica claro que o ritmo de produção é dependente da permeabilidade. Na figura 3 foi observado que onde há maior permeabilidade há maior produção.

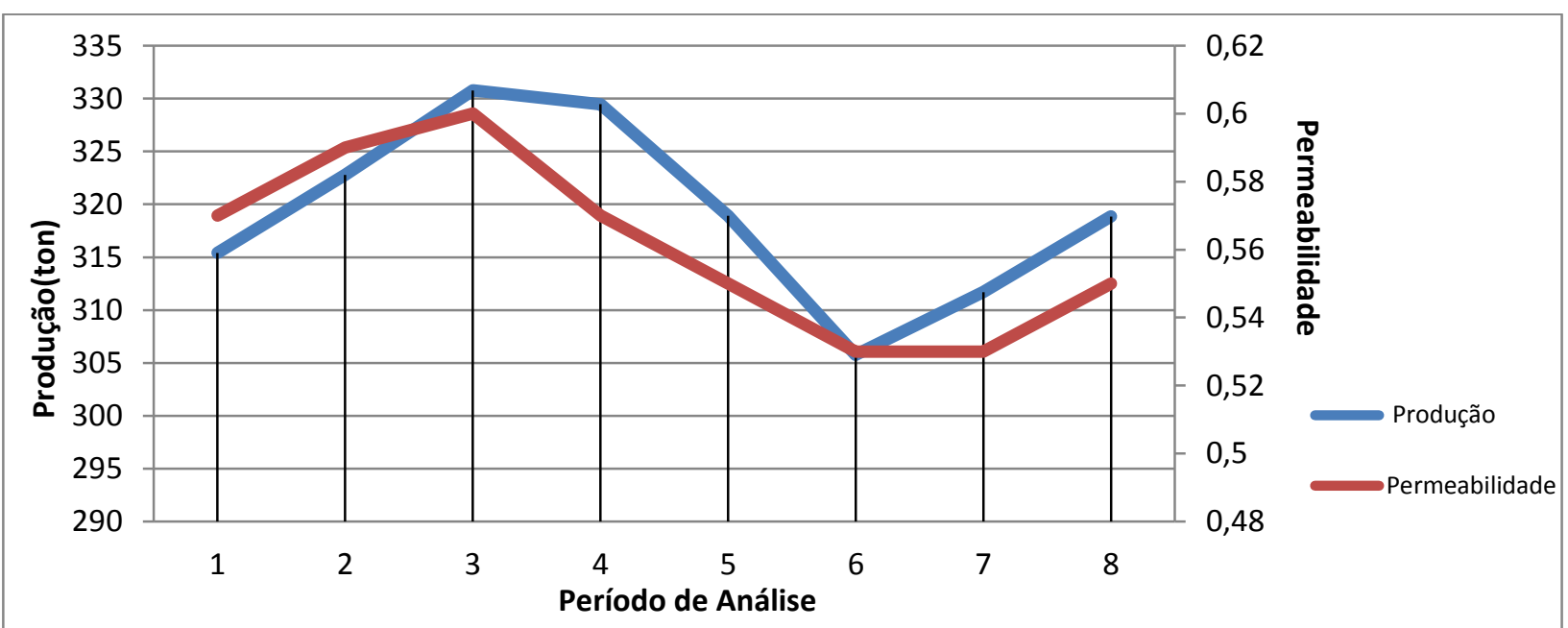

Figura 3 - Produção Vs Permeabilidade. Fonte: Dados Sidermin, 2013.

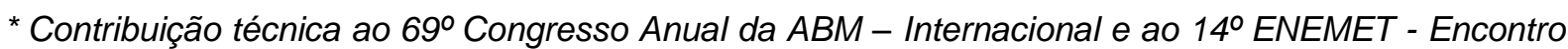
Nacional de Estudantes de Engenharia Metalúrgica, de Materiais e de Minas, 21 a 25 de julho de 2014, São Paulo, SP, Brasil. 


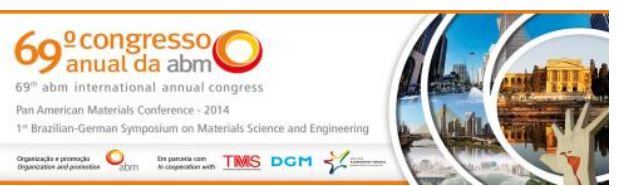

Assim é possível observar a correlação entre permeabilidade e produção, demonstrando à dependência do ritmo de produção a permeabilidade da carga.

Os finos gerados dentro do alto-forno em sua maior parte são procedentes de um peneiramento ineficiente ou crepitação do minério de ferro, o gás de topo utilizado nos secadores de minério tem como objetivo otimizar o peneiramento e minimizar o fenômeno de crepitação além do pré-aquecimento da carga metálica.

O período apresentado a seguir vai do dia 23 a 30 , sendo tal posteriormente comparado ao período de 15 a 22. Essa comparação foi feita de forma a concretizar os fundamentos teóricos a respeito do assunto crepitação, demonstrando seus efeitos na produção e ressaltando os benefícios da utilização do mecanismo de secagem do minério de ferro.

$\mathrm{Na}$ figura a seguir, serão expostos os valores da produção no período onde o mecanismo de secagem do minério foi desativado.

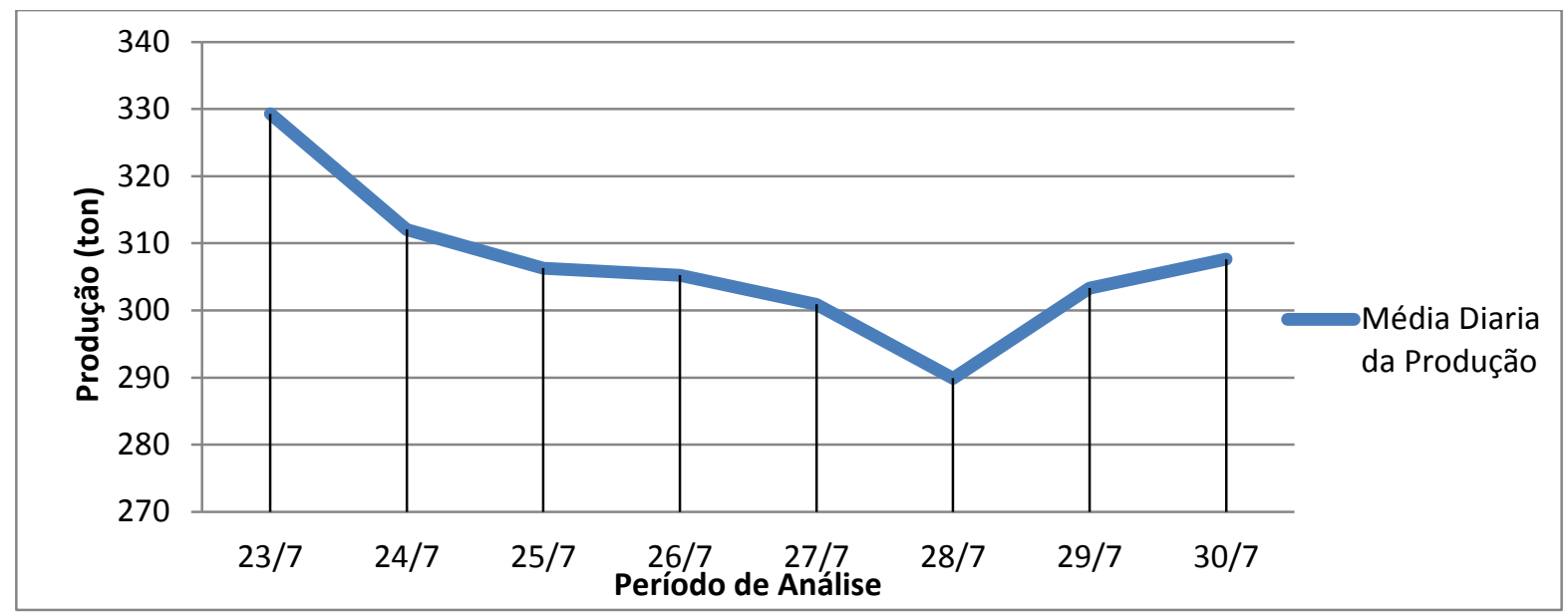

Figura 4 - Produção com Secador de Minérios Desativado. Fonte: Dados Sidermin, 2013.

Como foi citado anteriormente, a meta de produção do alto-forno 2 é de 310 toneladas por dia, sendo que a maior parte dos dias do período estudado na figura 4 ficam abaixo da meta, onde o dia 28 é apontado como dia critico na produção.

Essa fase do estudo que apresenta os dados do secador de minérios desativado faz evidenciar a perda de permeabilidade que será apresentada na figura 5.

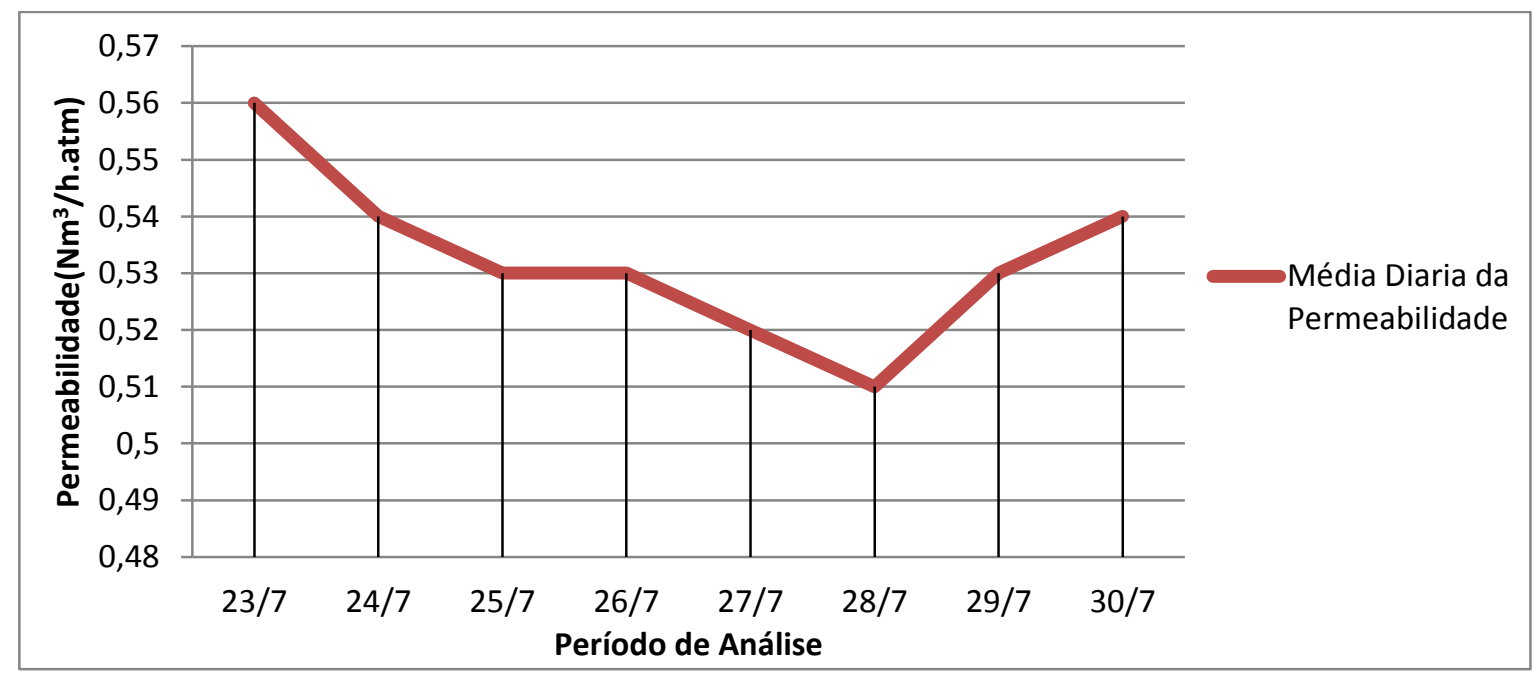

Figura 5 - Permeabilidade com Secador de Minérios Desativado. Fonte: Dados Sidermin, 2013.

* Contribuição técnica ao 69 Congresso Anual da ABM - Internacional e ao 14ํㅡㄹ ENET - Encontro Nacional de Estudantes de Engenharia Metalúrgica, de Materiais e de Minas, 21 a 25 de julho de 2014, São Paulo, SP, Brasil. 


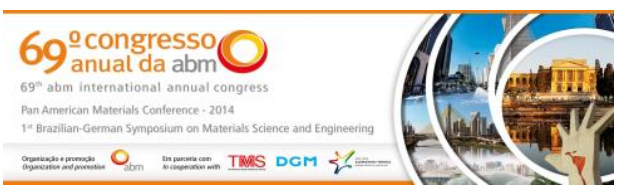

Fazendo uma analogia com o período onde o secador de minério estava ativo é possível verificar a queda de permeabilidade em relação ao período onde o secador de minério estava ativo.

Na figura 6, é feita a relação da produção versus a permeabilidade.

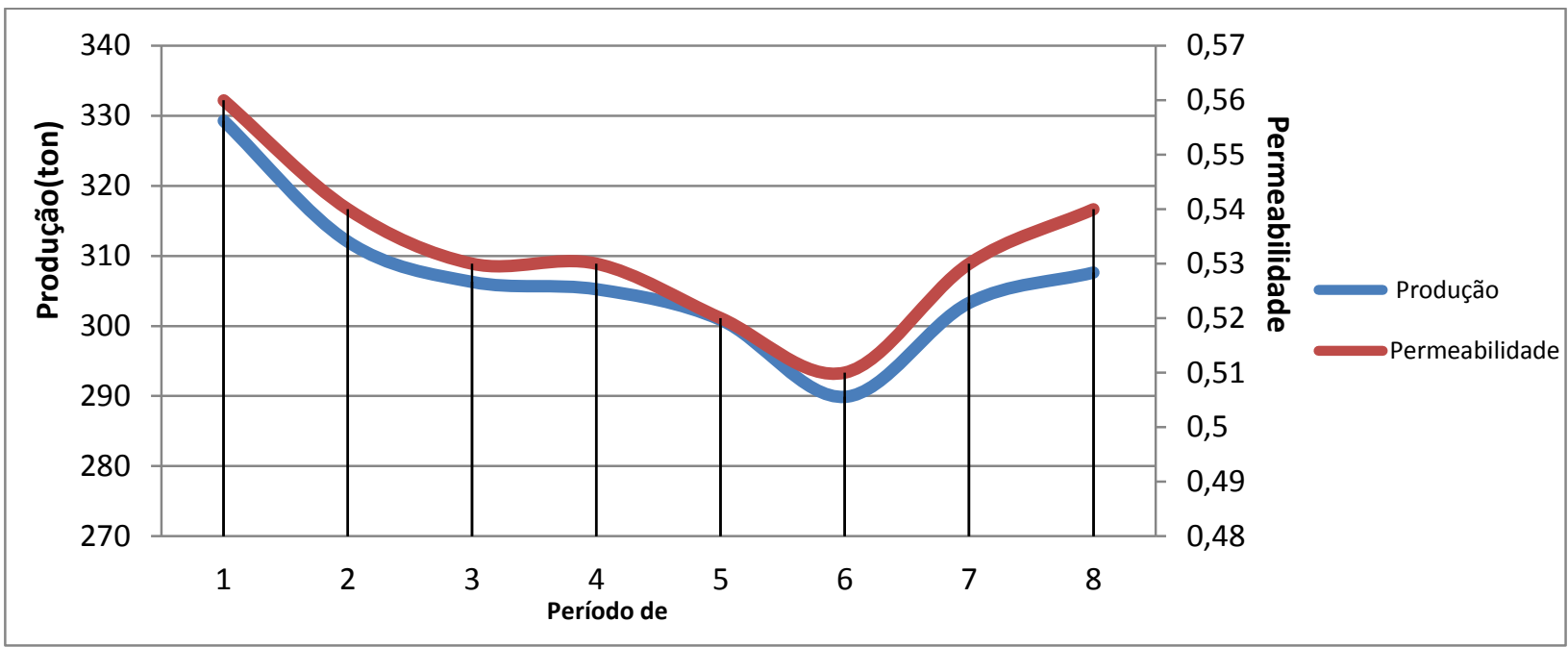

Figura 6 - Produção Vs Permeabilidade. Fonte: Dados Sidermin, 2013.

É mostrado no gráfico que a perda de permeabilidade afeta diretamente na produção, onde que no dia 28 o Alto-Forno apresentou menor permeabilidade, dessa forma se valida a importância da secagem do minério, visando evitar a geração de finos por otimização do peneiramento, e no caso estudado um alívio de tensão através de um tratamento térmico que resultará na crepitação do minério no silo de alimentação, evitando a geração de finos dentro do alto-forno.

Seguindo a linha comparativa, na figura 7 é feita a relação entre a figura 1 e 4 , fazendo uma analogia entre os dois períodos estudados.

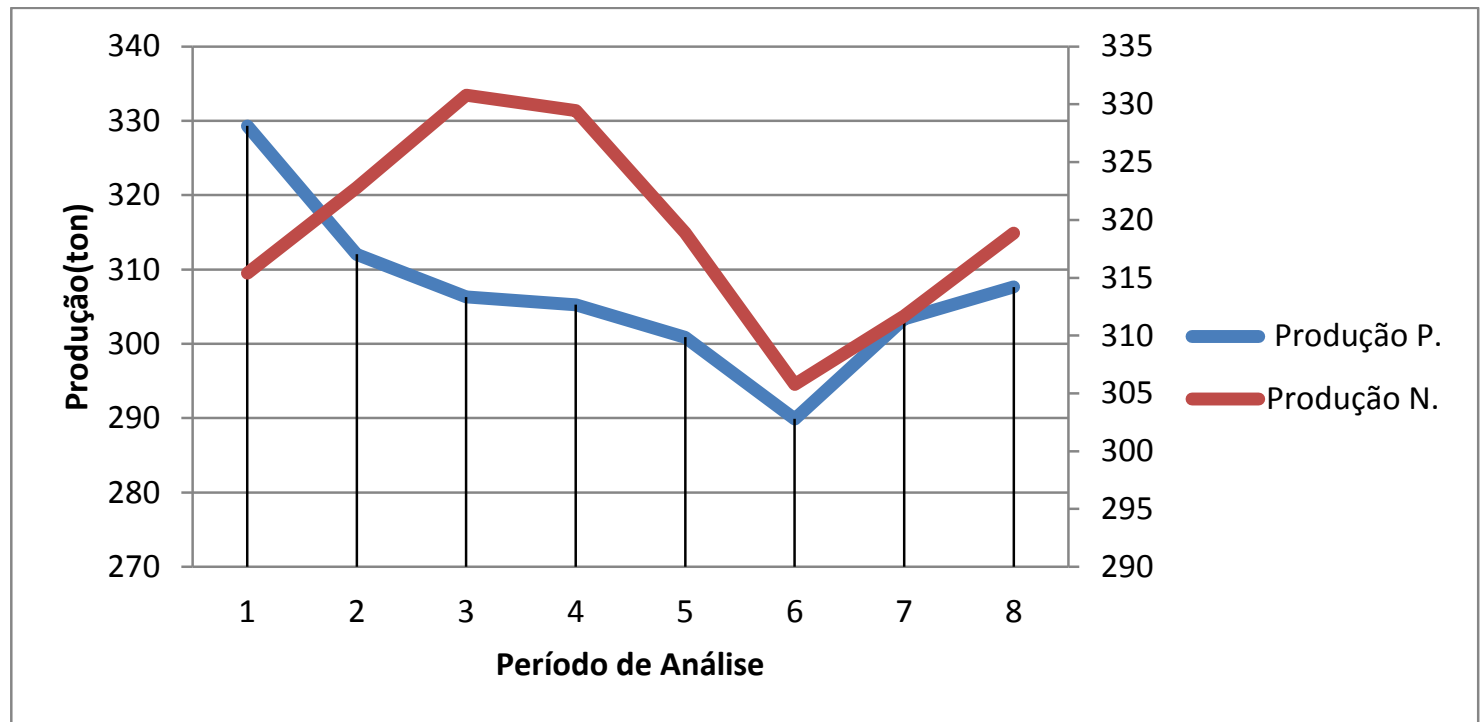

Figura 7 - Produção com Secador de Minério Ativado e Desativado. Fonte: Dados Sidermin, 2013.

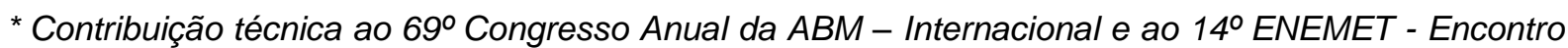
Nacional de Estudantes de Engenharia Metalúrgica, de Materiais e de Minas, 21 a 25 de julho de 2014, São Paulo, SP, Brasil. 


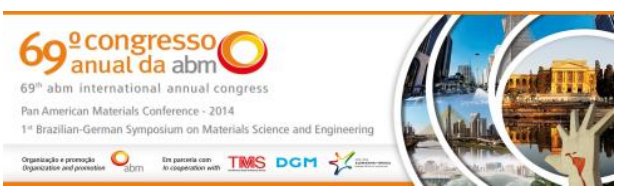

É visto no gráfico acima que a utilização do gás de topo como fonte de calor para secagem do minério é vantajosa em termos de produção, diminuindo a geração de finos dentro do alto-forno, melhorando assim a permeabilidade.

Os resultados mostram uma tendência de que o índice de crepitação será menor quando se utiliza o processo de secagem, mantendo-se o índice sempre abaixo do limite de cada análise. Desta forma observa-se uma melhora considerável no índice de crepitação de minérios que sofreram o tratamento térmico. Essa melhora se reflete na permeabilidade do alto-forno, pois a geração de finos foi menor, otimizando o processo e dando um melhor ritmo de produção no processo.

Foi feito um levantamento econômico dos dois períodos estudados, onde se objetivou demonstrar os ganhos econômicos gerados pela utilização do mecanismo de secagem do minério de ferro, sendo esse mecanismo passivo de melhorias no peneiramento e amenizador do fenômeno de crepitação por tratamento térmico. $\mathrm{O}$ valor de venda da tonelada métrica de ferro-gusa na ocasião da pesquisa era de $R \$$ 750,00 , dados da Sidermin (2013).

Analisando os dados de produção nas tabelas 2 a 5, observa-se que no período que o mecanismo de secagem do minério de ferro estava ativo a produção foi maior, gerando dessa forma um montante em valor econômico maior do que o período onde o mecanismo de secagem estava desativado.

A tabela 2 faz menção aos valores da produção no período onde o mecanismo de secagem estava desativado

Tabela 2 - Ganhos - Secador Desativado.

\begin{tabular}{|l|l|}
\hline \multicolumn{2}{|l|}{ Produção Secador Desativado } \\
\hline Dia & Produção - Kg \\
\hline $23 / 07 / 2013$ & 329,300 \\
\hline $24 / 07 / 2013$ & 312,040 \\
\hline $25 / 07 / 2013$ & 306,300 \\
\hline $26 / 07 / 2013$ & 305,260 \\
\hline $27 / 07 / 2013$ & 300,900 \\
\hline $28 / 07 / 2013$ & 289,900 \\
\hline $29 / 07 / 2013$ & 303,320 \\
\hline $30 / 07 / 2013$ & 307,640 \\
\hline Total em Peso $(\mathrm{Kg})$ & 2454,660 \\
\hline $\begin{array}{l}\text { Total em Valor } \\
\text { (Reais) }\end{array}$ & $\mathrm{R} \$ 1.840 .995,00$ \\
\hline
\end{tabular}

Fonte: Dados Sidermin, 2013.

Já na tabela 3 é exposto os dados da produção no período onde o mecanismo de secagem do minério de ferro estava ativo.

* Contribuição técnica ao $69^{\circ}$ Congresso Anual da ABM - Internacional e ao 14ํㅡㄹ ENEMET - Encontro Nacional de Estudantes de Engenharia Metalúrgica, de Materiais e de Minas, 21 a 25 de julho de 2014, São Paulo, SP, Brasil. 
Tabela 3 - Ganhos - Secador Ativado

\begin{tabular}{|c|c|}
\hline \multicolumn{2}{|c|}{ Produção Secador Ativado } \\
\hline Dia & Produção - Kg \\
\hline $15 / 07 / 2013$ & 315,400 \\
\hline $16 / 07 / 2013$ & 322,780 \\
\hline $17 / 07 / 2013$ & 330,780 \\
\hline $18 / 07 / 2013$ & 329,460 \\
\hline $19 / 07 / 2013$ & 318,900 \\
\hline $20 / 07 / 2013$ & 305,760 \\
\hline $21 / 07 / 2013$ & 311,700 \\
\hline $22 / 07 / 2013$ & 318,860 \\
\hline Total em Peso (Kg) & 2553,640 \\
\hline $\begin{array}{c}\text { Total em Valor } \\
\text { (Reais) }\end{array}$ & $\mathrm{R} \$$ \\
\hline
\end{tabular}

Fonte: Dados Sidermin, 2013.

A tabela 4 apresenta os resultados encontrados dos índices de crepitação dos minérios de ferro $A$ e $B$ amostrados sem tratamento térmico.

Tabela 4 - Índice de Crepitação Amostra sem Tratamento Térmico

\begin{tabular}{|l|l|l|}
\hline & Minério A $(20-25 \mathrm{~mm})$ & Minério B $(20-25 \mathrm{~mm})$ \\
\hline$I_{6,3}$ & $6,9 \%$ & $5,8 \%$ \\
\hline$I_{3,35}$ & $3,7 \%$ & $3,3 \%$ \\
\hline$I_{0,6}$ & $1,2 \%$ & $0,6 \%$ \\
\hline
\end{tabular}

Fonte: Dados Sidermin, 2013.

A tabela 5 observa os resultados encontrados dos índices de crepitação da amostra coletada no silo de alimentação, que passou pelo processo de secagem pelo gás de topo.

Tabela 5 - Índice de Crepitação Amostra com Tratamento Térmico

\begin{tabular}{|l|l|l|}
\hline & Minério A $(20-25 \mathrm{~mm})$ & Minério B $(20-25 \mathrm{~mm})$ \\
\hline$I_{6,3}$ & $4,1 \%$ & $3,9 \%$ \\
\hline$I_{3,35}$ & $2,2 \%$ & $2,0 \%$ \\
\hline$I_{0,6}$ & $0,6 \%$ & $0,5 \%$ \\
\hline
\end{tabular}

Fonte: Dados Sidermin, 2013.

O período onde se utilizou o mecanismo de secagem foi mais produtivo, os dados de produção comparativos entre os dois períodos são demonstrados na tabela 6 .

Tabela 6 - Diferença entre Secador Ativado e Desativado

\begin{tabular}{|c|c|}
\hline Produção - Secador Desativado (Kg) & 2454,660 \\
\hline Produção - Secador Ativado (Kg) & 2553,640 \\
\hline Diferença em Peso (Kg) & 98,980 \\
\hline Diferença em Valor (Reais) & $\mathrm{R} \$ 74.235,00$ \\
\hline
\end{tabular}

Fonte: Dados Sidermin, 2013.

\footnotetext{
* Contribuição técnica ao 69 Congresso Anual da ABM - Internacional e ao $14^{\circ}$ ENEMET - Encontro Nacional de Estudantes de Engenharia Metalúrgica, de Materiais e de Minas, 21 a 25 de julho de 2014, São Paulo, SP, Brasil.
} 


\section{CONCLUSÃO}

A utilização do gás de topo como um método de pré-tratamento térmico do minério de ferro possibilitou uma melhora no índice de crepitação e otimização do peneiramento pelos resultados obtidos bem como uma melhora no produtividade da Sidermin. Durante o período do ano de 2013 em que o Secador de Minério esteve ativo na empresa Sidermin, ela produziu 98,980Kg de Ferro Gusa a mais do que no período que o mecanismo estava desativado. Totalizando um ganho excedente de $\mathrm{R} \$ 74.235,00$ no faturamento do período.

Desta forma pode se afirmar que o gás de topo, co-produto do processo de fabricação do ferro-gusa, apresenta viabilidade econômica para implantação como meio de otimização do processo de peneiramento e amenizador do fenômeno de crepitação.

\section{Agradecimentos}

Os autores são gratos ao CNPq - Conselho Nacional de Desenvolvimento Cientifico e Tecnológico pelo apoio financeiro, sob a forma de bolsa. A Sidermin Siderúrgica Mineira pelo apoio a pesquisa e seu desenvolvimento.

\section{REFERÊNCIAS}

1 Birnbaum $\mathrm{H}$. Essais sur minerais em morceaux em vue de la determination de leur comportament au haut four-neau. CIT, (10): 2069-2089, 1960.

2 Kunii K. A Study on the decrepitation of iron ores. Testsu - to - Hagané, 1996, 52 (3):228-230.

3 Faria GL. Estudo da Intensidade de Crepitação de Minérios Granulados de Manganês do Brasil, Tese de Mestrado. Universidade Federal de Ouro Preto, Ouro Preto, 2008.

4 Vieira CB, Krüger FL, Araújo FGS, Vieira JB. Secagem e tratamento térmico de granulados de minérios de ferro para uso em reatores de redução: Aplicação em usinas siderúrgicas brasileiras. 6th IAS Ironmaking Conference, Rosário, Argentina. 2007.

5 http://www.cemig.com.br/ptbr/A_Cemig_e_o_Futuro/inovacao/Alternativas_Energeticas/Documents/25BalancoEnerg eticoRev.pdf. Acesso em 08 de janeiro de 2014.

6 Araújo LA. Manual de Siderurgia, São Paulo: Editora Arte \& Ciência, Volume 2. 1997.

7 ISO/CD 8731 - Iron ores for blast furnace feedstocks - Determination of the decrepitation index. ISO/TC 102/SC3. 2004.

8 Vieira CB. Estudo Básico da Qualidade Intrínseca de Minérios de Ferro para Altos Fornos. Tese de Doutorado. Universidade Federal de Minas Gerais, Belo Horizonte, 1996.

* Contribuição técnica ao 69ํ Congresso Anual da ABM - Internacional e ao 14º ENEMET - Encontro Nacional de Estudantes de Engenharia Metalúrgica, de Materiais e de Minas, 21 a 25 de julho de 2014, São Paulo, SP, Brasil. 